Bedingungen für eine Gäbrung schon durch den Zustand, in welchem sich der Organismus befindet, gegeben sind.

Ueber die Quelle der Hefezellen erhielt ich, wie ich glaube, sicheren Aufschluss durch eine Arbeit, welche anfänglich nicht den geringsten Zusammenhang mit der eben erwähnten zu haben schien. Ich untersuchte nämlich die sogenannte Leptothrix buccalis, welche allnächtlich in der Mundhöble der meisten Menschen wächst, besonders auf den Zähnen und auf der Zunge. Dieses Pfänzchen ist keine Alge, wie man bisher annahm, sondern geht ebenfalls aus dem Penicillium hervor und zwar durch Umbildung der Sporen.

Lässt man Sporen von Penicillium crustaceum in reinem Wasser stehen, so gelangt ein Theil derselben, wenn auch langsam, zur Keimung, während ein grosser Theil sich wesentlich verändert. Die Sporen werden blass, platzen nach einigen Tagen und entlassen schwärmende Körncben, welche keimen und Leptothrix-Fäden hervorbringen. Bringt man die Leptothrix ans der Mundhöble in eine gährungsfäbige Flüssigkeit, so bilden sich sehr bald Gährungszellen und zwar auf den Plasmakörpern, welche in bestimmten Abständen in den Leptothrix-Gliedern liegen. Man kann alle Zwischenstufen zwischen den in Freiheit gesetzten Plasmakörpern selbst und ausgebildeten Hefezellen nachweisen, die sich durch Abschnürung rasch vermehren. Ganz ehenso verhielt sich die künstlich aus Penicillium erzeugte Leptothrix. Ist die Flüssigkeit aber nicht gährungsfähig, dann entstehen aus den Plasmakörpern durch Keimung neue Leptothrix-Fäden in ungeheuerer Menge. Die erhöhte Temperatur der Mundhöhle scheint die Leptothrix-Bildung sehr zu begünstigen.

Lässt man die Diphtheritis-Hefe auf organischer Materie vegetiren, so entstehen stets Leptothrix-Fäden. Dadurch wird es noch mehr als wabrscheinlich, dass die Leptothrix-Hefe mit der Diphtheritis-Hefe identisch ist und dass diese aus den Leptothrix-Fäden hervorgeht. Ist das aber richtig, so muss nothwendig schon ein krankhafter Zustand des menechlichen Organismus der Hefebildung den Boden zubereitet haben.

3.

\title{
Ueber die Contractilität der Zellen der Milzpulpe.
}

\author{
Von Dr. J. Cohnheim in Berlin.
}

Die enge Beziehung der Milz zum Blute, sowie die grosse Aehnlichkeit zwischen den Zellen der Milzpulpe und den farblosen Blut- und Lymphkörpercben legte die Wahrscheinlichkeit nahe, dass auch den ersteren Contractilităt innewohne, und liess es wünschenswerth erscheinen, den Versuch, welchen W. Müller in Rücksicht bierauf, jedoch ohne Erfolg, hei einem Salamander angestellt*), zu wiederholen. In der That gelingt es, unter Beobachtung der von Recklinghausen hervorge-

*) W. Müller, Ueber den feineren Bau der Milz. S. 21 . 
hobenen Vorsichtsmaassregeln, ohne Schwierigkeit, sich bei allen Wirbelthierklassen von den Bewegungserscheinungen der Milzzellen zu ïberzengen.

Man unterscheidet bekanntlich in der Pulpe kleinere, einkernige und grössere, ein- oder mehrkernige farblose, ferner grössere Körnchen und Pigment führende Zellen; alle diese lassen sich bei jedem Schnitt durch die Pulpe in grosser Menge isoliren, und schwimmen, zumal wenn man über den Schnitt ganz leicht mit der Nadel oder dem Pinsel hinstreicht, in sehr beträchtlicher Anzahl in der Umgebung des Schnittes frei in der Zusatzlüssigkeit. Behandelt man in solcher Weise einen feinen, der Milz eines eben getödteten Frosches entnommenen Schnitt und bringt ihn unter Serum in die feuchte Kammer, so erscheinen bei sofortiger Besichtigung die bei Weitem meisten farblosen Zellen als ganz runde Bildungen; sie sind sehr blass, mattglänzend, nirgend siebt man einen Kern. Aber schon nach kurzer Frist erblickt man ganz andere Figuren; die farblosen Körperchen sind oval geworden, nach einer Seite spitz zulaufend, vielfach sind Zacken und Ausläufer hervorgetreten: kurz, es zeigen sich ganz dieselben Bilder, dieselben fortlaufenden Formveränderungen, wie sie seit längerer Zeit an den Lymphkörperchen und jetzt ja auch an den Eiter- und Bindegewebskörperchen bekannt sind; nicht selten erscheint während dieser Gestaltveränderungen mit vollkommener Deutlichleit der Kern, um vielleicht alsbald wieder in der Tiefe der Zelle dem Auge zu entschwinden.

W. Müller hat sich bei der Anstellung seines Versuchs von vornherein gegen den Einwand sicher zu stellen gesucht, dass es lediglich dem Blutstrom der Milz angebörige und durch den Schnitt frei gewordene farblose Blutzellen seien, deren Bewegungserseheinungen man wahrnehme. Indess kann ick die Berechtigung dieses Einwandes niclt anerkennen. Für einmal äbertrifft die Zahl der farblosen Zellen die der farbigen, deren allerdings ziemlich viele im Gesichtsfelde umber liegen, um ein so Beträchtliches, dass ganz gewöbnlich das umgekehrte Verbältniss, wie beim Blute selber, hier statt hat, dass also schon desshalb jeder Gedanke, man habe hier bloss Blutzellen vor sich, von der Hand gewiesen werden muss: die Formveränderungen aber zeigen sich an allen Zellen ohne Unterschied. Für's Zweite aber sind, wie erwähnt, der Milzpulpe einige Zellformen eigentbümlich, die ị̣ normalen kreisenden Blute und der Lymphe sich nicht finden, die Körnchen- und Pigmentzellen. Gerade an diesen aber, in welchen die Pigmentkügelchen und Körnchenhaufen selbst so gute Anhaltspunkte zur Fixirung gewähren, bieten die Formveränderungen das allerfrappanteste Phänomen; bald siebt man den Körnchenhaufen am vorderen Ende der wurstförmig ausgezogenen Zelle, bald am hinteren; bald schieben sich zu beiden Seiten blasse Flügel des Zellprotoplasma hervor, bald liegt er im Centrum eines sternartigen Gebildes; die bedeutende Grösse dieser Zellen ässt ' thei ibre Bewegungen nur nm so ausgiebiger erscheinen.

b babe jedoch auch versucht, in der von Müller selbst vorgeschlagenen

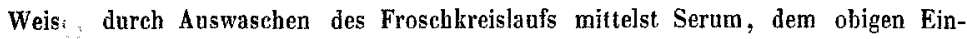
wande zu begegnen, obwohl es mir nicht ganz zweifellos erschien, ob es gelingen würde, selbst im günstigsten Falle, auch alle farblosen Blutkörperchen aus dem Kreislaufe zo verdrängen: Nach diesem Verfahren erscheint die Milz zuweilen ein wenig vergrössert, immer beller, als sonst; auf einem Schnitte sieht man jetzt 
meist nur farblose Zellen, während die farbigen hie und da in vereinzelten, kleinen Häufchen zusammengedrängt, dabei vielfach verhogen, geknickt erscheinen. Das ist aber auch alle Differenz; die Bewegungen aller farblosen Zellen stehen an Lebhaftigkeit un Nichts denen der Zellen aus der unausgewaselienen Milz nach.

Alles, was bisher vom Frosch gesagt worden, gilt ebenso für die Milzzellen der Fische, von denen ich Perca fluviat. darauf untersucht habe.

Es gilt aber insbesontere anch für die Säugethiere. Auch beim Kaninchen und Meerschweinchen babe ieh auf's Evidenteste die Formyeränderungen der Milzzellen beobachtet, freilich nicht mit derselben Ausgiebigkeit, derselben Lebhaftigkeit und derselben Dauer, wie bei den Fröschen, bei denen die Contractilität durch eine ganze Reihe von Stunden sicb erbält. Von einigem Interesse war es mir dabei, dass in der Milz eines des Meerschweincben vereinzelte sogenannte blutkörperhaltige Zellen sich fanden und auch diese die Bewegungserscheinungen nicht vermissen liessen.

4.

\title{
Der Abortus, in seiner Bedeutung für die Berölkertungszunahme betrachtet.
}

\author{
Von Dr. med. W. Stricker, \\ pract. Arzte in Frankfurt a. M.
}

Neben der Sterblichkeit der Kinder in den ersten Lebensjahren, zu deren Statistik ich in diesem Archive (Bd. XXXII. S. 390) Beiträge geliefert habe, steht der Abortus als Hemmniss einer naturgemässen Bevölkerungszunahme obenan. Dennoch ist meines Wissens dieser Gegenstand nocb nicht seiner Wichtigkeit gemäss dargestellt worden, da die Geburtshelfer nur die medicinische Seite desselben zu betrachten plegen und die Ethnographen mit einer bei fiir ein gemischtes Publikum bestimmten Werken ganz wohl angebrachten Zuräckhaltung diese Seite des Geschlechtslebens der Völker berühren. Indessen, während wir für die civilisirten Staaten Europa's auf die Annalen der Strafrechtspflege beschränkt sind, welche uns gelegentlich einen Blick auf einzelne Fälle einef langjährigen Proxis thun lassen, wird der Abortus bei anderen Völlkern mit einer Offenheit geäbt, ẃelche es ärztlichen Reisenden leicht macht, umfassende Aufschiüsse zu geben, aus denen die Wichtigkeit der Sitte für die Bevölkerungswissenschaft bervorgebt. Im Folgenden sollen einzelne Notizen aus solchen Werken zusammengestellt werden.

L or. Rigler, weiland Lehrer der medic. Klinik zu Constantinopel (Die Türkei und deren Bewohner. Wien, 1852. I. 206, 207., II. 330), berichtet, dass mit $\mathrm{zu}$ den Ursachen des frübzeitigen Alterns der türkischen Frauen, ihrer meist unregelmässigen Menstruation, der Blutungen und vielfachen Erkrankungen der Geschlechtsorgane und der Unfruchtbarkeit, die zur Abtreibung der Leibesfrucht - in Fällen, wo man aus finanzieller Rücksicht oder zur Erhaltung der Reize eine zahlreiche 